\title{
Characterization of stress tolerant high potential ethanol producing yeast from agro-industrial waste
}

\author{
Md. Fakruddin ${ }^{1}$, Md. Ariful Islam², Md. Abdul Quayum², Monzur Morshed Ahmed ${ }^{\text {*, }}$ \\ Nayuum Chowdhury ${ }^{2}$ \\ ${ }^{1}$ Industrial Microbiology Laboratory, Institute of Food Science and Technology, Bangladesh Council of Scientific and Industrial Research, \\ Dhaka, Bangladesh \\ ${ }^{2}$ Department of Biotechnology, Brac University, Dhaka, Bangladesh
}

\section{E mail address:}

monzur_29@yahoo.com(M. M. Ahmed)

\section{To cite this article:}

Md. Fakruddin, Md. Ariful Islam, Md. Abdul Quayum, Monzur Morshed Ahmed, Nayuum Chowdhury. Characterization of Stress Tolerant High Potential Ethanol Producing Yeast from Agro-Industrial Waste. American Journal of BioScience. Vol. 1, No. 2, 2013, pp. 24-34. doi: 10.11648/j.ajbio.20130102.11

\begin{abstract}
Bioethanol or biofuel as an alternative to fossil fuels has been expanded in the last few decades in the whole world. Use of bioethanol as a renewable transportation fuel will minimize the amounts of fossil-derived carbon dioxide $\left(\mathrm{CO}_{2}\right)$ to the Earth's atmosphere. Yeast is the most favorite organism for ethanol production because of its diverse substrate specificity and ease of production of ethanol under anaerobic condition. The main objective of this research work was to isolate \& characterize stress tolerant, high potential ethanol producing yeast strains from agro industrial waste. In total 4 yeast isolates have been characterized on the basis of morphological and physico-chemical characters. Based on morphological appearance of vegetative cell under microscope, ascospore production, colony character and physicochemical characters all the strains was identified to be Yeast. Phylogenetic identification by DNA sequencing confirmed that the strain P is Saccharomyces Unisporus, strain C is Saccharomyces cerevisiae, strain T is Saccharomyces cerevisiae \& strain DB2 is Candida piceae. Most of the strains were thermotolerant, $\mathrm{pH}$ tolerant, ethanol tolerant as well as osmotolerant. They were resistant to cycloheximide at $0.0015 \mathrm{~g} / 100 \mathrm{ml}$ concentration, hydrogen peroxide $(0.50 \%)$, Chloramphenicol $(30 \mu \mathrm{g} / \mathrm{disc})$ but growth was inhibited in the presence of $1 \%$ acetic Acid. The strains $\mathrm{P}, \mathrm{C} \& \mathrm{~T}$ showed good Invertase activity \& only the $\mathrm{T}$ strain was capable of producing killer toxin. They were capable of fermenting glucose, fructose, sucrose, amylose \& trehalose. Ethanol producing capability of the strains was studied using sugarcane molasses as substrate. The bioethanol production capacity of the yeasts were found to be $15 \%, 14.5 \%, 12 \% \& 8.15 \%$ for $\mathrm{P}, \mathrm{C}, \mathrm{T} \& \mathrm{DB} 2$ respectively at $\mathrm{pH} 6.0,30^{\circ} \mathrm{C}$ temperature in media with $5.5 \%$ initial reducing sugar concentration in shaking condition. Pilot scale ethanol production by P strain was $13.10 \%$, C strain $11.15 \%$, T strain $9.80 \%$ \& DB2 strains $7.85 \%$ at 60 hours. These strains could be potential for ethanol production from cane molasses.
\end{abstract}

Keywords: Ethanol, Molasses, DNA Sequencing, Stress Tolerant

\section{Introduction}

Nowadays, ethanol production from renewable resources has received great attention because of the increasing petroleum shortage ${ }^{(1)}$. Biomass fuels such as ethanol are renewable and help reducing greenhouse gas emissions from fosssil fuels ${ }^{(2)}$. Such renewable energy sources are indigenous and can therefore contribute to reducing dependency on oil imports and increasing security of supply ${ }^{(3)}$.

Bioethanol can contribute to a cleaner environment and with the implementation of environment protection laws in many countries; demand is increasing ${ }^{(4)}$. Saccharomyces cerevisiae is one of the oldest, most exploited and best studied microorganism in both old and new biotechnologies and is known to be the world's premier industrial microorganisms which readily convert sugar into alcohol and $\mathrm{CO}_{2}$ in metabolic process called fermentation ${ }^{(5)}$. Saccharomyces strains were used widely and traditionally for industrial ethanol production because of its ability to produce high concentrations of ethanol from hexoses and its high tolerance to ethanol and other inhibitory compounds $^{(6)}$. Bioethanol produced from renewable biomass, such as sugar, starch or lignocellulosic materials, 
is one of the alternative energy resources, which is both renewable and environmentally linked ${ }^{(7)}$. Tolerance to high temperatures and high ethanol concentrations are important properties of microorganisms of interest to industry ${ }^{(8)}$.The ability of yeast to produce ethanol depends on many factors such as strains, growth factors and optimum environmental conditions $^{(9)}$.

The aim of this study was to characterize stress tolerant yeast strains capable of producing high level of ethanol from molasses.

\section{Material and Methods}

\subsection{Collection of Strain}

The yeast strains were isolated from agro industrial wastes of Bangladesh. The strains were coded as P, C, T \& DB2.

\subsection{Identification of Yeast Isolates}

The yeast strains were characterized based on their cultural characteristics (Colony shapes, pigment, elevation, edge and surface appearance). Morphological and biochemical characterization of the isolated yeasts was performed according to Boboye and Dayo-Owoyemi ${ }^{(10)}$.

\subsection{Ascospore Formation}

Selected yeast strains were examined for ascospore formation according to Kurtzman et al. ${ }^{(11)}$

\subsection{Pseudomycelium Formation}

Following Kreger-van $\mathrm{Rij}^{(12)}$ the formation of pseudomycelium was investigated by slide culture technique.

\subsection{Sugar Fermentation}

Yeast fermentation broth base with Durham tube was used for testing of yeasts for carbohydrate fermentation. The carbohydrates used were Glucose (dextrose), Fructose, Sucrose, Lactose, Galactose, Maltose, Trehalose, Raffinose, Ribose, Arabinose, Rhamnose and Xylose. The color of the medium changed from blue to yellow due to the formation of acids and gas produced ${ }^{(13)}$.

\subsection{Thermo tolerance}

YPD liquid medium was used for determination of thermotolerance. The initial optical density of each tube was recorded on spectrophotometer at $600 \mathrm{~nm}$ against the medium as blank. All cultures were incubated at $37^{\circ} \mathrm{C}$, $40^{\circ} \mathrm{C}, 41^{\circ} \mathrm{C}, 42^{\circ} \mathrm{C}, 43^{\circ} \mathrm{C}, 44^{\circ} \mathrm{C}, 46^{\circ} \mathrm{C}$ and $48^{\circ} \mathrm{C}$ for 48 hours for observing thermo tolerance of yeast strain. The increase in optical density in a tube was recorded as evidence of growth $^{(14)}$.

\subsection{PH Tolerance}

YEPD broth was prepared at different $\mathrm{pH}$. Each McCartney contained $15 \mathrm{ml}$ of YEPD media with different $\mathrm{pH}$ and blank media was used as a control. Then each was inoculated by half loopful of Yeast cell and measured the initial optical density at $600 \mathrm{~nm}$ and incubated at $30^{\circ} \mathrm{c}$ for $48 \mathrm{hrs}$. After $48 \mathrm{hrs}$ cell density was further recorded at 600 $\mathrm{nm}$ for growth ${ }^{(15)}$.

\subsection{Ethanol Tolerance}

YPD liquid medium was used for determination of ethanol tolerance. Concentrations of absolute ethanol was varied from 5 to $20 \%(\mathrm{v} / \mathrm{v})$ and then added to different flask The initial optical density of each flask was read off on spectrophotometer at $600 \mathrm{~nm}$ against the medium as blank. All cultures were incubated at $30{ }^{\circ} \mathrm{C}$ for 48 hours. The increase in optical density in a flask was recorded as evidence of growth. The concentration of alcohol at which the growth of yeasts was just inhibited was assessed as the ethanol tolerance of yeasts ${ }^{(16)}$.

\subsection{Osmo tolerance}

YEPD broth was prepared containing 5\%, 8\%, 10\%, $12 \%, 15 \%, 18 \%$ and $20 \%$ of $\mathrm{NaCl}$. Each McCartney contained $15 \mathrm{ml}$ of YEPD liquid media with appropriate concentration of salt and blank media was used as a control. Then each was inoculated by half loopful of Yeast cell and measured the initial optical density at $600 \mathrm{~nm}$ and incubated at $30^{\circ} \mathrm{c}$ for $48 \mathrm{hrs}$. After $48 \mathrm{hrs}$ cell density was further recorded at $600 \mathrm{~nm}$.

\subsection{Sugar Tolerance}

The procedure by Ekunsanmi and Odunfa ${ }^{(17)}$ was employed for observation of sugar tolerance. YEPD broth was prepared containing $10 \%, 15 \%, 30 \%, 45 \%$ \& $50 \%$ of different sugars. Each McCartney contained $15 \mathrm{ml}$ of YEPD liquid media with appropriate concentration of salt and blank media was used as a control. Then each was inoculated by half loopful of Yeast cell and measured the initial optical density at $600 \mathrm{~nm}$ and incubated at $30^{\circ} \mathrm{C}$ for $48 \mathrm{hrs}$. After $48 \mathrm{hrs}$ cell density was further recorded at 600 $\mathrm{nm}$. The increase in optical density in a flask was recorded as evidence of growth.

\subsection{Acetic Acid Tolerance}

YEPD broth was prepared containing 1\% of Acetic Acid. Each McCartney contained $15 \mathrm{ml}$ of YEPD liquid media with $1 \%$ concentration of Acetic Acid and blank media without Acetic Acid was used as a control. Then each was inoculated by half loopful of Yeast cell and the initial optical density were measured at $600 \mathrm{~nm}$ and incubated at $30^{\circ} \mathrm{C}$ for $48 \mathrm{hrs}$. After $48 \mathrm{hrs}$ cell density was further recorded at $600 \mathrm{~nm}$. 


\subsection{Cycloheximide Resistance}

YEPD agar medium was used for determination of Cycloheximide resistance. Cycloheximide antibiotic $(0.0015 \mathrm{~g})$ was added into $100 \mathrm{ml}$ autoclaved YEPD agar media and inoculated by yeast cells and incubated for 48 hours.

\subsection{Chloramphenicol Resistance}

YPD agar medium was used for determination of Chloramphenicol resistance. Chloramphenicol antibiotic disc $(30 \mu / \mathrm{L})$ was placed into the center of the already inoculated petridish. Then the plate kept at $30^{\circ} \mathrm{C}$ for growing. The zone of inhibition by the disc was recorded as an evidence of Chloramphenicol sensitivity ${ }^{(18)}$.

\subsection{Hydrogen per Oxide Resistance}

Petridish containing the solid YEPD agar media was inoculated by yeast cells. Then three discs containing $30 \mu 1$, $20 \mu \mathrm{l}$ and $10 \mu \mathrm{l}$ of Hydrogen peroxide were placed on difference places on the plate. Hydrogen peroxide containing plates were incubated at $30^{\circ} \mathrm{c}$ for 48 hours.

\subsection{Invertase Activities}

Yeast strains grown on the agar slants were harvested by pouring sterile distilled water into the slants and gently scraping with a wire loop. The cells were washed, centrifuged and $0.1 \mathrm{~g}$ wet weight of each was re-suspended in $10 \mathrm{ml}$ of acetate buffer, $\mathrm{pH} 5.0^{(19)}$, sucrose solution (4\% $\mathrm{w} / \mathrm{v}, 2 \mathrm{ml}$ ) in the same acetate buffer was inoculated with $1 \mathrm{ml}$ of cell suspension for $5 \mathrm{~min}$ at $30^{\circ} \mathrm{C}$. The amount of reducing sugar released was determined by dinitro-salicylic acid method ${ }^{(20)}$. The amount of enzyme which liberate 1 $\mu$ mole reducing sugar per minute was defined as one unit of invertase activity.

\subsection{Killer Toxin Production Capacity}

Ribereau-Gayon et al. ${ }^{(21)}$ described the action of a killer strain on a sensitive strain is easy to demonstrate in the laboratory on an agar culture medium at $\mathrm{pH} 4.2-4.7$ at $20^{\circ}$ C. The sensitive strain is inoculated into the mass of agar before it solidifies; then the strain to be tested is inoculated in streaks on the solidified medium. If it is a killer strain, a clear zone in which the sensitive strain cannot grow encircles the inoculums streaks.

\subsection{DNA Extraction}

DNA extraction was done according to the procedure described by Moslem et el. ${ }^{(22)}$. Yeast cell was harvested for 3 days on YPD broth. About $1.5-\mathrm{ml}$ culture was centrifuged in micro-centrifuge tube and mixed well with $600 \mu \mathrm{l}$ DNA extraction buffer ( $200 \mathrm{mM}$ Tris- $\mathrm{HCl}, \mathrm{pH} 8.5,250 \mathrm{mM} \mathrm{NaCl}$, $25 \mathrm{mM}$ EDTA, $0.6 \%$ SDS $) .6 \mu \mathrm{l}$ RNAse A $(15 \mathrm{mg} / \mathrm{ml}$ final concentration) was added and vortexed and incubated at $65^{\circ} \mathrm{C}$ for 10 min. $140 \mu 1$ Protein Precipitation solution (3 M sodium acetate, $\mathrm{pH}$ 5.3) was added and the contents were mixed thoroughly by inverting the tubes. Tubes were then incubated at $-20^{\circ} \mathrm{C}$ for $5 \mathrm{~min}$ and after incubation centrifuged at 13,000 g for $5 \mathrm{~min}$. $600 \mu \mathrm{l}$ of the supernatant was carefully transferred to a new micro-centrifuge tube and $600 \mu \mathrm{l}$ absolute isopropanol was added to it and mixed by inverting gently 30 times or by vortexing. The tube was stored at room temperature for $5 \mathrm{~min}$ and then Centrifuged at $12,000 \mathrm{~g}$ for $2 \mathrm{~min}$ at $4^{\circ} \mathrm{C}$. DNA was visible as a pellet that ranges in color from off-white to light green. DNA precipitate was washed twice with $650 \mu 175 \%$ ethanol. 90 $\mu 1$ DNA elution buffer (pre-warmed at $65^{\circ} \mathrm{C}$ ) was added and DNA was stored at $4^{\circ} \mathrm{C}$ until usage ${ }^{(23)}$.

\subsection{DNA Quantification}

DNA was quantified either by measuring the absorbance at $260 \mathrm{~nm}$ using the NanoDrop (ND-1000) spectrophotometer (NanoDrop Technologies).

\subsection{Phylogenetic Identification}

Primers used in this assay were nu-SSU-0817-5, (TTAGCATGGAATAATRRAATAGGA) and nu-SSU1196-3' (TCTGGACCTGGTGAGTTTCC) ${ }^{(24)}$. PCR reaction mixer was composed of $1 \mathrm{X}$ PCR buffer, $25 \mathrm{mM}$ $\mathrm{MgCl}_{2}, 10 \mathrm{mM}$ of each dNTP, $0.2 \mu \mathrm{l}$ Taq polymerase (5U/ $\mu 1), 20$ picomole of each of forward and reverse primer and $5 \mu 1$ template DNA. Total volume of reaction mixer was 30 $\mu 1$. PCR thermal cycler was set in the following program$94^{\circ} \mathrm{C}$ for $5 \mathrm{~min}, 35$ cycles of $94^{\circ} \mathrm{C}$ for $30 \mathrm{sec}, 57^{\circ} \mathrm{C}$ for 1 min $\& 72^{\circ} \mathrm{C}$ for $1 \mathrm{~min}$, final extension at $72^{\circ} \mathrm{C}$ for $10 \mathrm{~min}$. After thermal cycling, $15 \mu 1$ of the PCR product was loaded on the corresponding well of a $2 \%$ of agarose gel along with a 50-bp DNA ladder at 70 volts for about 1.5 hours and visualized by staining with $0.5 \%$ ethidium bromide and UV illumination at $302 \mathrm{~nm}$ to confirm PCR amplification.

Sequencing reactions were carried out using ABI-Prism Big dye terminator cycle sequencing ready reaction kit and the PCR products were purified by a standard protocol. The purified cycle sequenced products were analyzed with an ABI-Prism 310 genetic analyzer. The chromatogram sequencing files were edited using Chromas 2.32. The homology of the 5.8S rDNA gene sequences was checked with the 5.8S rDNA gene sequences of other organisms that had already been submitted to GenBank database using the BLASTN (http:/ /www.ncbi.nih.gov/BLAST/) algorithm. Evolutionary analyses were conducted in MEGA $5^{(25)}$.

\subsection{Molasses Pretreatment}

Before the molasses is used for fermentation, it undergoes an initial treatment, the purpose of which is to remove the sludge (colloids, firm particles, sand and to kill unwanted organisms) etc. $1 \mathrm{~kg}$ molasses is diluted with 0.5 $\mathrm{L}$ water and $0.001 \%$ conc. Sulfuric acid were added. It was then heated to the boiling and kept standing for couple of hours before use ${ }^{(26)}$. 


\subsection{Ethanol Production from Fermentation of Molasses}

Composition of fermentation media was Molasses 250 gm/L, Urea $0.10 \mathrm{gm} / \mathrm{L}$ and Conc. $\left(\mathrm{H}_{2} \mathrm{SO}_{4}\right) 0.30 \mathrm{ml} / \mathrm{L}$ and pH 6.0 with initial reducing sugar conc. 5.50\%. Fermentation was carried out in Erlenmeyer conical flasks. $250 \mathrm{ml}$ fermentation media was taken into $500 \mathrm{ml}$ Erlenmeyer flasks and then added the homogenous suspension of yeast was inoculated into the media in an aseptic condition. The flask was incubated at $30^{\circ} \mathrm{C}$ in a shaking incubator at $115 \mathrm{rpm}$ for 72 hours.

\subsection{Reducing Sugar Estimation}

The reducing substance (sugar) obtained due to the enzymatic reaction was determined by DNS method ${ }^{(27)}$.

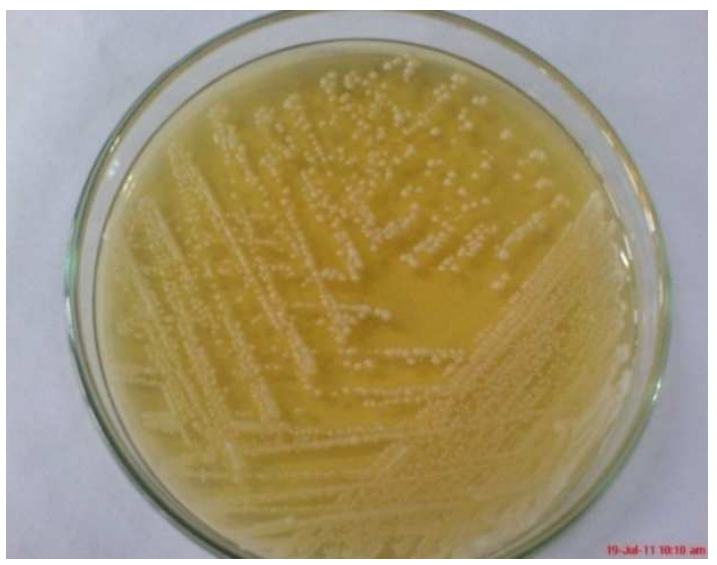

Fig 1. Growth in YPD medium

\subsection{Ascospore Formation}

Following the method of Kreger-van $\mathrm{Rij}^{(12)}$ and Kurtzman and Fell ${ }^{(31)}$, ascospores formation by the yeast isolate $\mathrm{P}, \mathrm{C}, \mathrm{T} \& \mathrm{DB}_{2}$ was detected for indication of the ascomycetous yeast. Ascospore formed in ascospore forming media after incubating for 3 weeks at $25^{\circ} \mathrm{C}$ (fig-3).

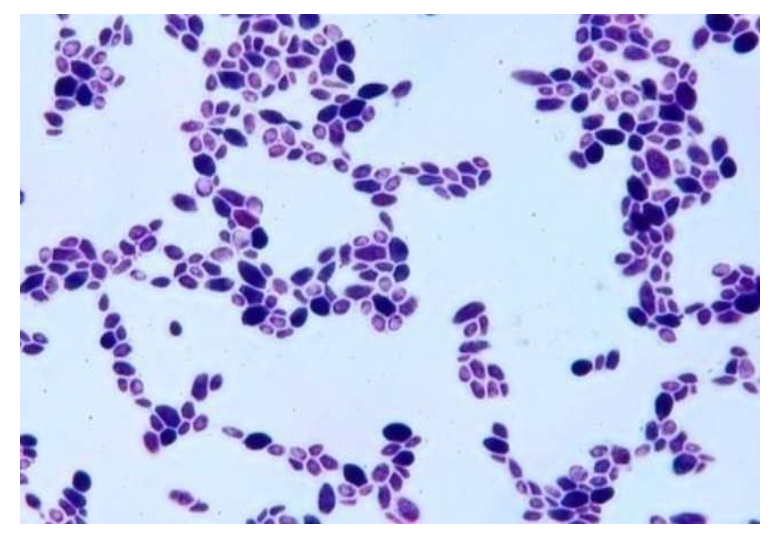

Fig 3. Ascospore formation observation under compound microscope

\subsection{Pseudo mycelium Formation}

The yeast isolate $\mathrm{P}, \mathrm{C}, \mathrm{T} \& \mathrm{DB} 2$ can produce

\subsection{Alcohol Estimation}

Alcohol percentage in the fermentation broth was measured by the method described by Conway ${ }^{(28)}$.

\section{Results}

\subsection{Identification of Yeast Isolates}

Based on the colony characteristics (white and creamy texture) ovoid microscope shape, the presence of ascospore and budding pattern (multipolar) (fig-1 \& fig-2), the selected isolate was found to belong Sacharomycestype unicellular ascomycete according to Lodder (29) and Boekhout and Kurtzman ${ }^{(30)}$.

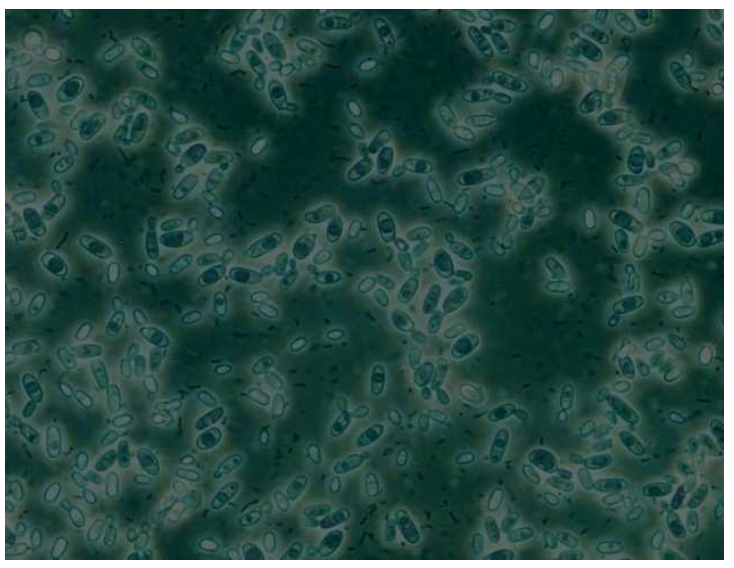

Fig 2. Cell morphology under compound microscope

pseudomycelium and showed in a filamentous form under microscope (Fig-5). Pseudomycelium formation is characteristic of Saccharomyces cerevisiae, which is dimorphic, existing either in a spherical, unicellular yeastlike morphology or in a filamentous form, termed pseudohyphae that results from elongated chains of cells that remain attached to one another ${ }^{(32)}$ (fig-4).

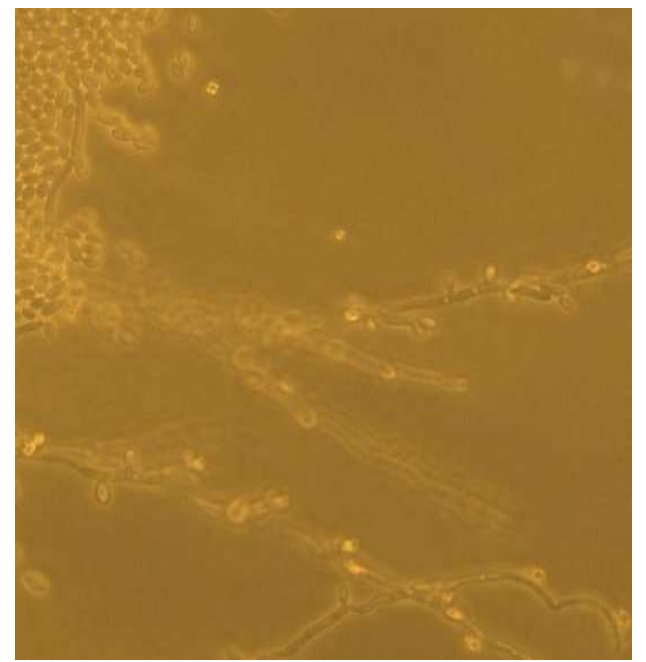

Fig 4. Elongated chain of Yeast pseudo mycelium under microscope 


\subsection{Sugar Fermentation}

In this study, the yeast isolates $\mathrm{P}, \mathrm{C}, \mathrm{T} \& \mathrm{DB} 2$ showed variation of utilization of eight different sugars. They were utilized glucose, fructose, sucrose, maltose $\&$ trehalose but failed to grow on lactose and xylose, rhamnose, raffinose \& arabinose $^{(30)}$.
The thermotolerant yeast could promote high yield of ethanol at high temperature. Thermotolerant yeasts are capable of growth and fermentation during the summer months in non-tropical countries as well as under tropical climates ${ }^{(33)}$. The yeast isolates was found to be thermotolerant as they can grow up to $46{ }^{\circ} \mathrm{C}$ (fig-5).

\subsection{Thermo tolerance}

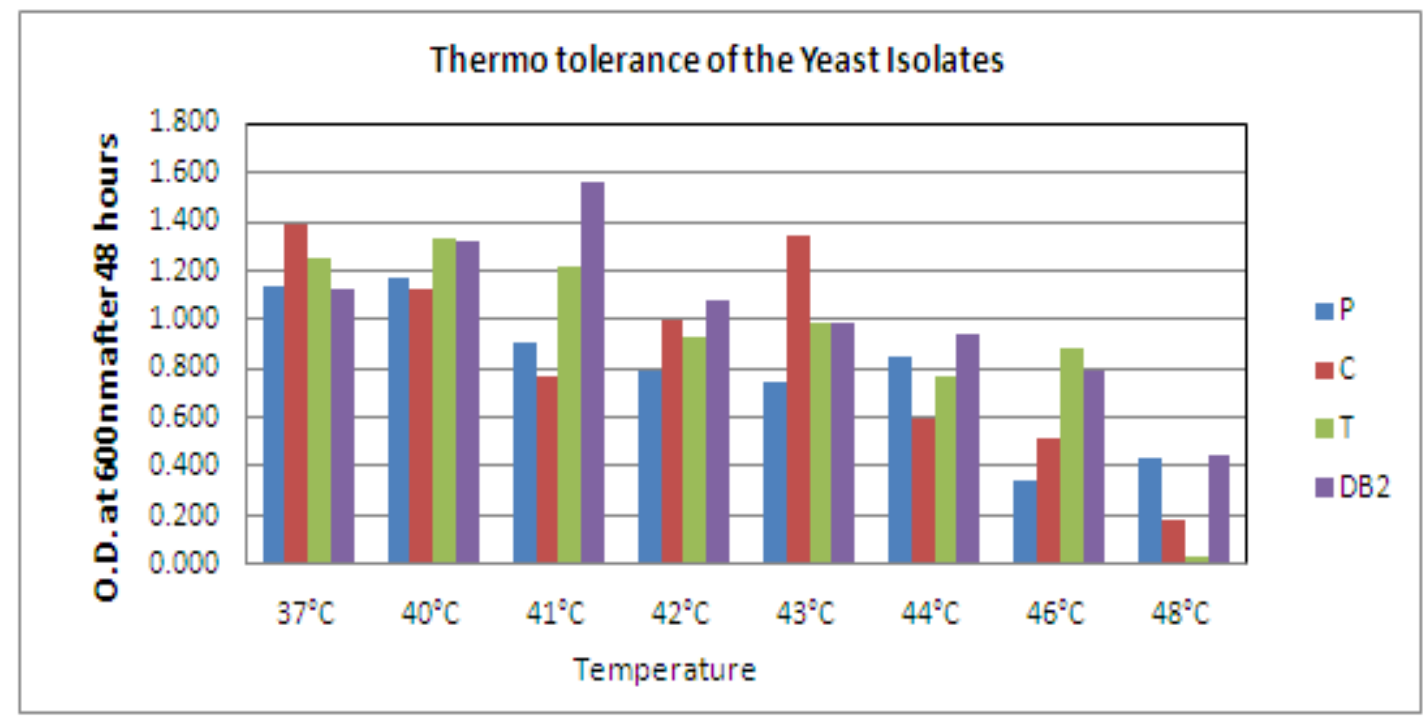

Fig 5. Thermo tolerance of the yeast isolates

\subsection{PH Tolerance}

The strains $\mathrm{P}, \mathrm{C}, \mathrm{T} \& \mathrm{DB} 2$ able to grow at wide range of $\mathrm{pH}$ (2 to 10$)$. At $\mathrm{pH} 2$, growth was decreased by highly acidic condition but can grow up to $\mathrm{pH} 10$. Maximum growth was seen at $\mathrm{pH} 6$ (fig-6).

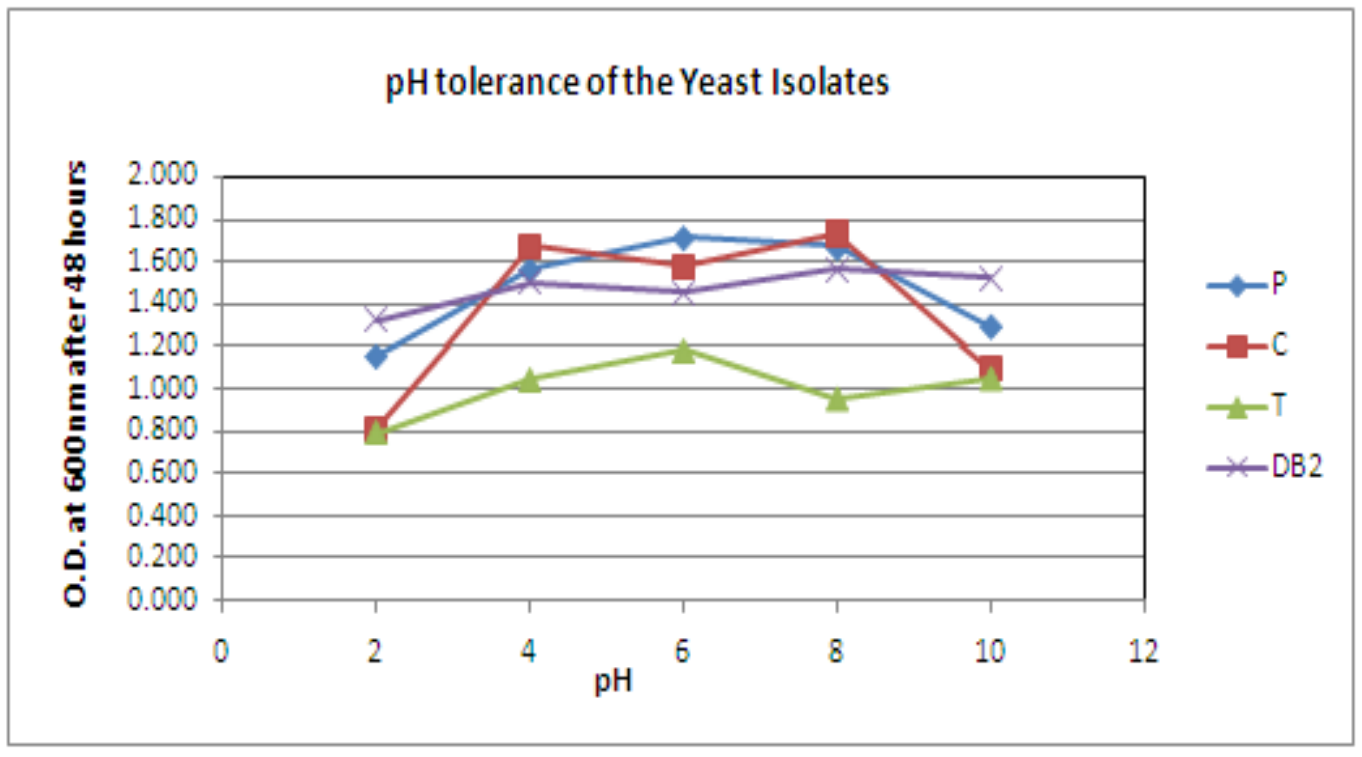

Fig 6. PH tolerance of the yeast isolates

\subsection{Ethanol Tolerance}

The thermotolerant yeast strains $\mathrm{P}, \mathrm{C}, \mathrm{T} \& \mathrm{DB} 2$ were grown at $0-20 \%(\mathrm{v} / \mathrm{v})$ ethanol concentration. $\mathrm{P} \& \mathrm{C}$ strains can grow well upto $18 \%(\mathrm{v} / \mathrm{v})$ and remained lowest in $20 \%$ $(\mathrm{v} / \mathrm{v})$ but $\mathrm{T} \&$ DB2 were upto $15 \%(\mathrm{v} / \mathrm{v})$. Only slight 
differences were observed in the growth rates with increasing ethanol concentration from 15 to $20 \%$ (v/v) (fig-

7).

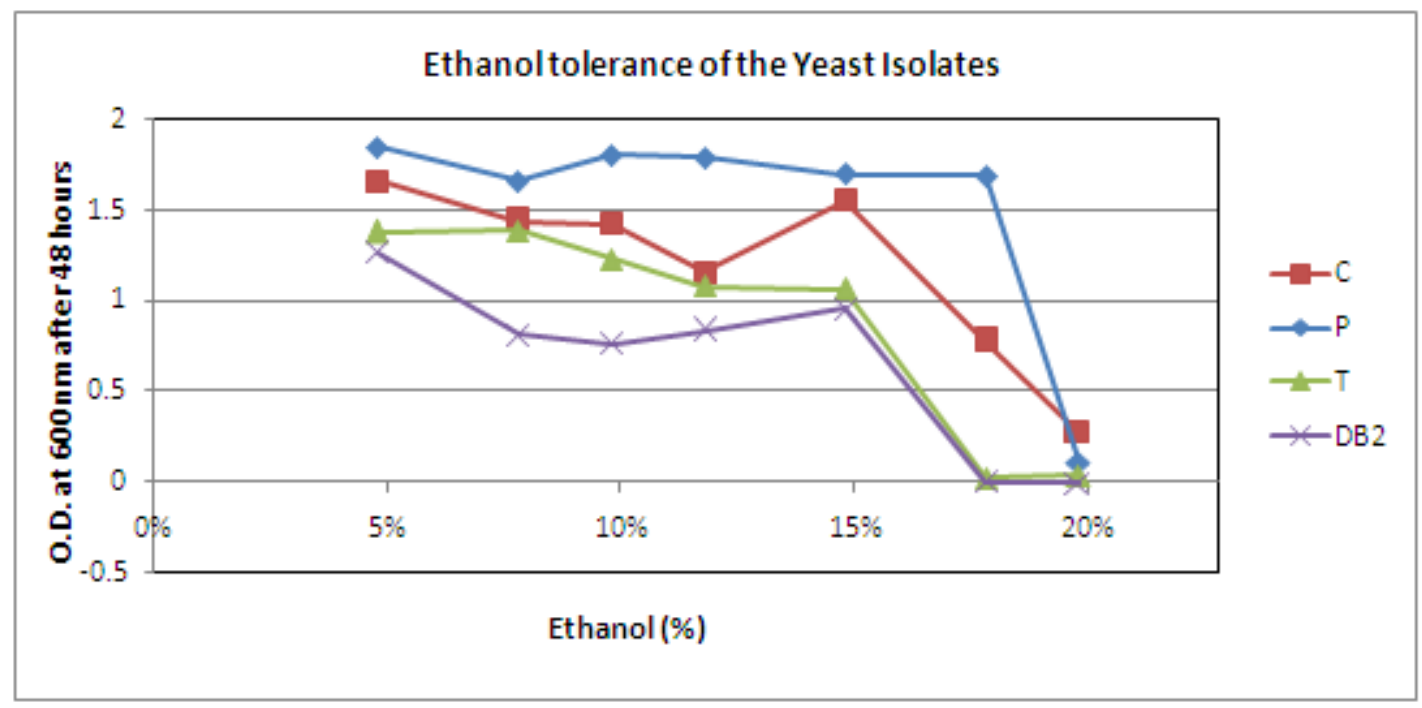

Fig 7. Ethanol tolerance of the yeast isolates

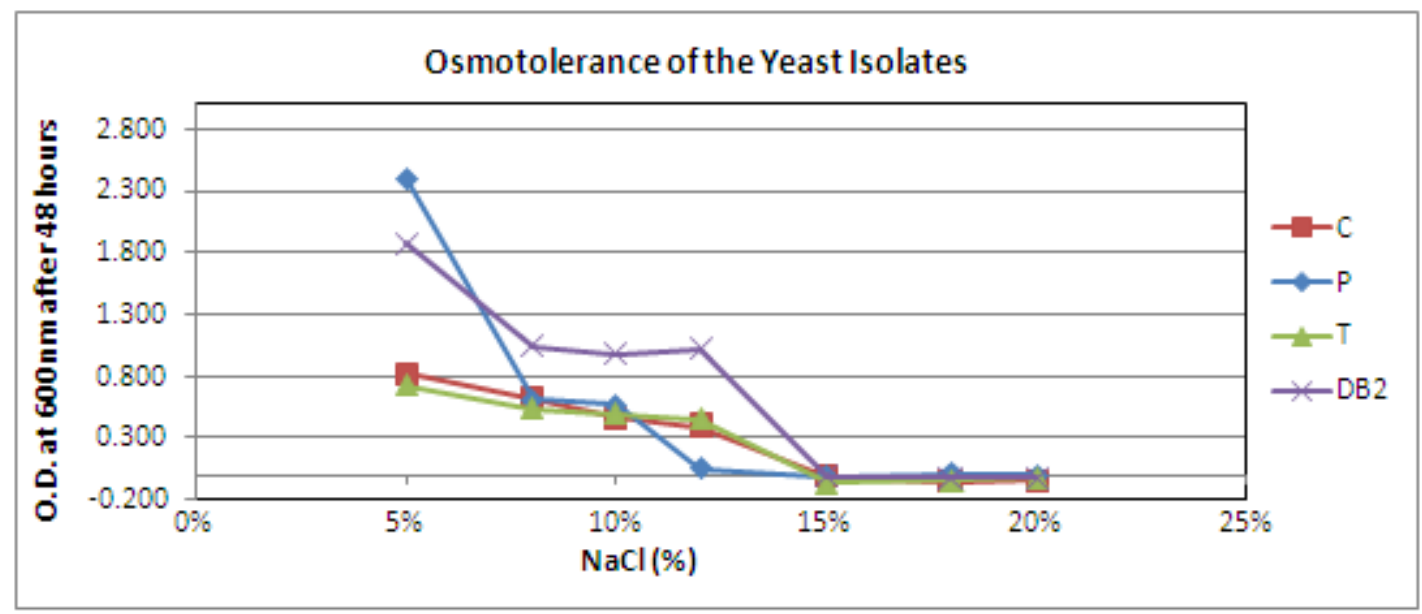

Fig 8. Osmotolerance of the yeast isolates

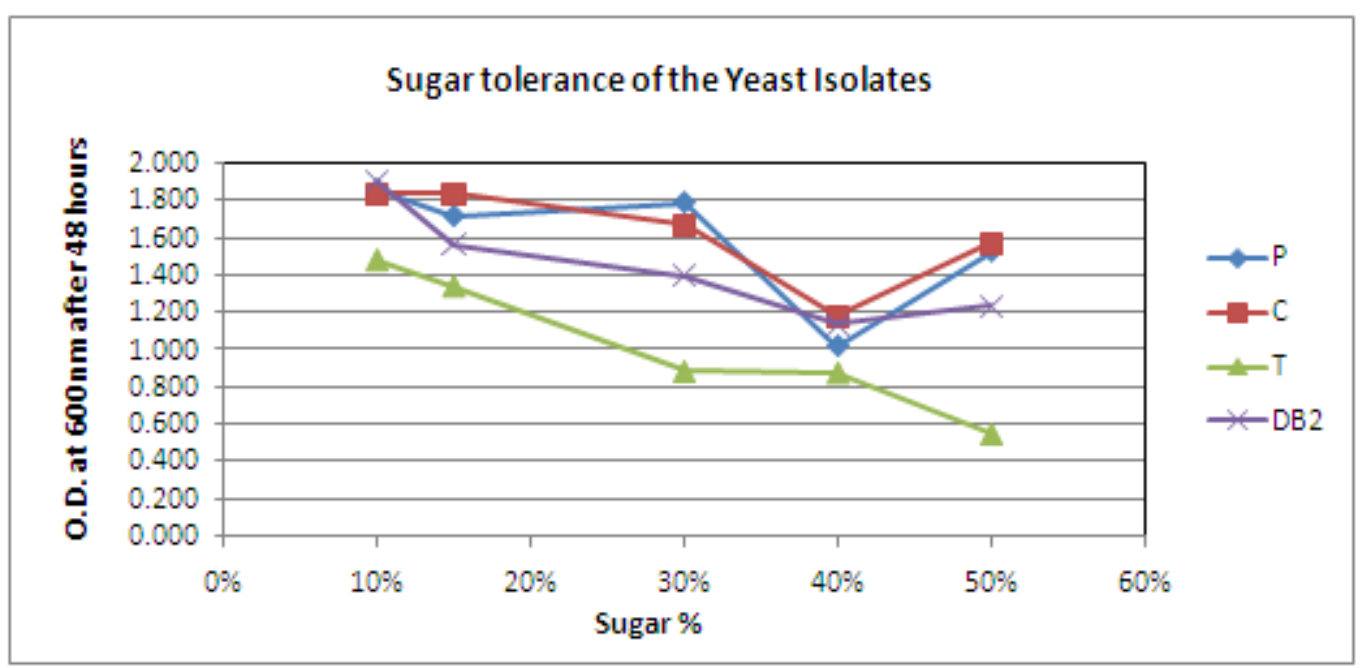

Fig 9. Sugar tolerance of the yeast isolates 


\subsection{Osmo Tolerance}

The strains P, C, T \& DB2 can tolerate up to $12 \%$ sodium chloride salt concentration but at higher concentration growth was reduced (fig-8).

\subsection{Sugar Tolerance}

The strains P, C, T \& DB2 can toterate upto $50 \%$ sugar $\&$ maximum growth was seen at $15 \%$ (fig-9).

\subsection{Acetic Acid Tolerance}

$1 \%$ Acetic acid usually inhibits the growth of yeasts. In this study, $1 \%$ Acetic acid inhibited the growth off all the 4 yeast strains in liquid YPED media.

\subsection{Cycloheximide Resistance}

The selected yeast strains were resistant to cycloheximide which is characteristic of $S$. cerevisiae ${ }^{(34)}$. It showed very good growth pattern on media with cycloheximide at $0.0015 \mathrm{~g} / 100 \mathrm{ml}$ concentration (Fig-10).

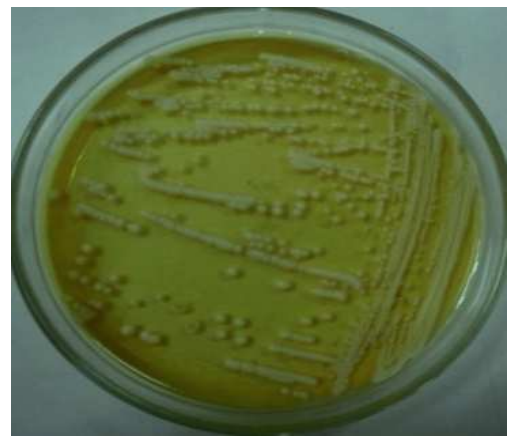

Fig 10. Growth on Cycloheximide containing solid YEPD agar media at $30^{\circ} \mathrm{C}$.

\subsection{Chloramphenicol Resistance}

All the selected 4 yeast strains were resistant to Chloramphenicol at $30 \mu \mathrm{g} / \mathrm{ml}$ concentration. They showed very good growth pattern against Chloramphenicol $30 \mu \mathrm{g} / \mathrm{ml}$ disk in YPD plate (Fig-11).

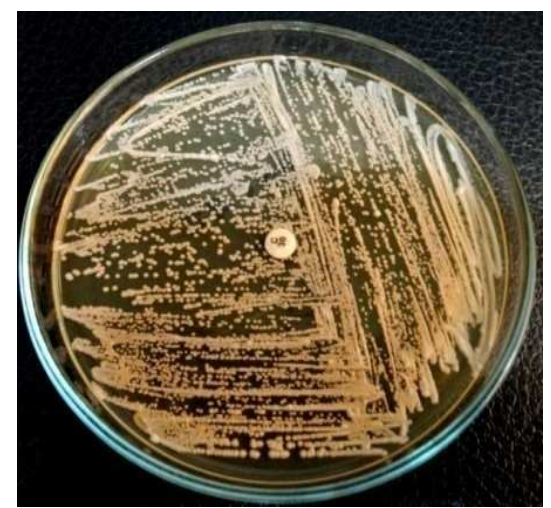

Fig 11. Growth on Chloramphenicol containing solid YEPD agar media at $30^{\circ} \mathrm{C}$

\subsection{Hydrogen per Oxide Resistance}

Hydrogen peroxide usually inhibits the growth of $S$. cerevisiae $^{(35)}$. All the yeast strains in this study were also resistance to hydrogen peroxide which is also a characteristic of $S$. cerevisiae $^{(34)}$.

\subsection{Invertase Activity}

All the isolates exhibited very good Invertase activity. They were capable of breakdown sucrose into Glucose \& Fructose. Invertase activity of the isolates were presented in table 1.

Table 1. Invertase activity of the selected Yeast Strains:

\begin{tabular}{cc}
\hline Name of the Strains & Invertase activity $(\boldsymbol{\mu m o l} / \mathbf{m i n})$ \\
\hline $\mathrm{DB} 2$ & 7.79 \\
$\mathrm{P}$ & 17.86 \\
$\mathrm{C}$ & 17.14 \\
$\mathrm{~T}$ & 15.50 \\
\hline
\end{tabular}

\subsection{Killer Toxin}

Among all 4 strains only strain $\mathrm{T}$ was found to be capable of producing killer toxin \& clear zone of inhibition was observed (fig 12).

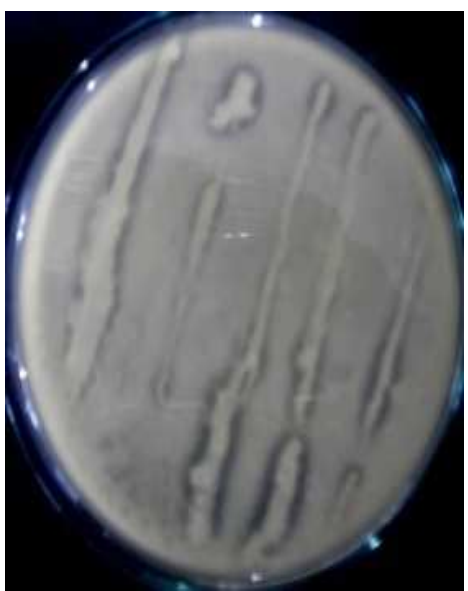

Fig 12. Observation of Zone of Inhibition due to Yeast killer toxin

\subsection{Phylogenetic Identification}

Identification by DNA sequencing of the isolates was shown in table 2. Phylogenetic analysis by MEGA 5 
showed that the isolates are phylogenetically distinct to other closely related species. Figure 13 shows the evolutionary positions of the isolates as revealed by $5.8 \mathrm{~s}$ rDNA sequencing.

Table 2. Phylogenetic Identification of the Yeast Strains:

\begin{tabular}{lll}
\hline Strain Name & Identification & Accession number \\
\hline $\mathrm{P}$ & Saccharomyces unisporous & AY046228.1 \\
$\mathrm{C}$ & Saccharomyces cerevisiae & HM134859.1 \\
$\mathrm{T}$ & Saccharomyces cerevisiae & $\mathrm{DQ} 295800.1$ \\
$\mathrm{DB} 2$ & Candida piceae & $\mathrm{EF090821.1}$ \\
\hline
\end{tabular}

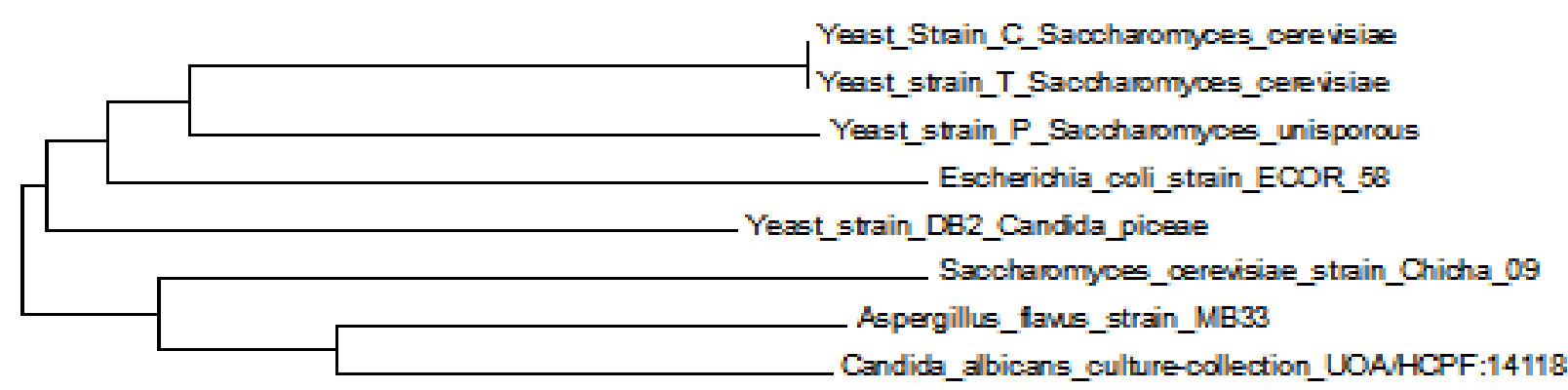

एण्ठ

Figure 13. Evolutionary relationships of taxa. The evolutionary history was inferred using the Neighbor-Joining method ${ }^{(36)}$. The optimal tree with the sum of branch length $=2.18969298$ is shown. The tree is drawn to scale, with branch lengths in the same units as those of the evolutionary distances used to infer the phylogenetic tree. The evolutionary distances were computed using the p-distance method ${ }^{(37)}$ and are in the units of the number of base differences per site. The analysis involved 8 nucleotide sequences. Codon positions included were 1 st $+2 n d+3 r d+N o n c o d i n g$. All positions containing gaps and missing data were eliminated. There were a total of 57 positions in the final dataset. Evolutionary analyses were conducted in MEGA5 ${ }^{(25)}$.

\subsection{Ethanol Production from Fermentation of Molasses}

In Shaking condition $(115 \mathrm{rpm})$, at $30^{\circ} \mathrm{C}$ using initial reducing sugar concentration of the fermentation media
$5.50 \%$ and $\mathrm{pH} 6.0$, maximum ethanol production was $15 \%$ by P strains, $14.50 \%$ by C strains, $12.00 \%$ by T $\& 8.15 \%$ by DB2 strains at 60 hours.

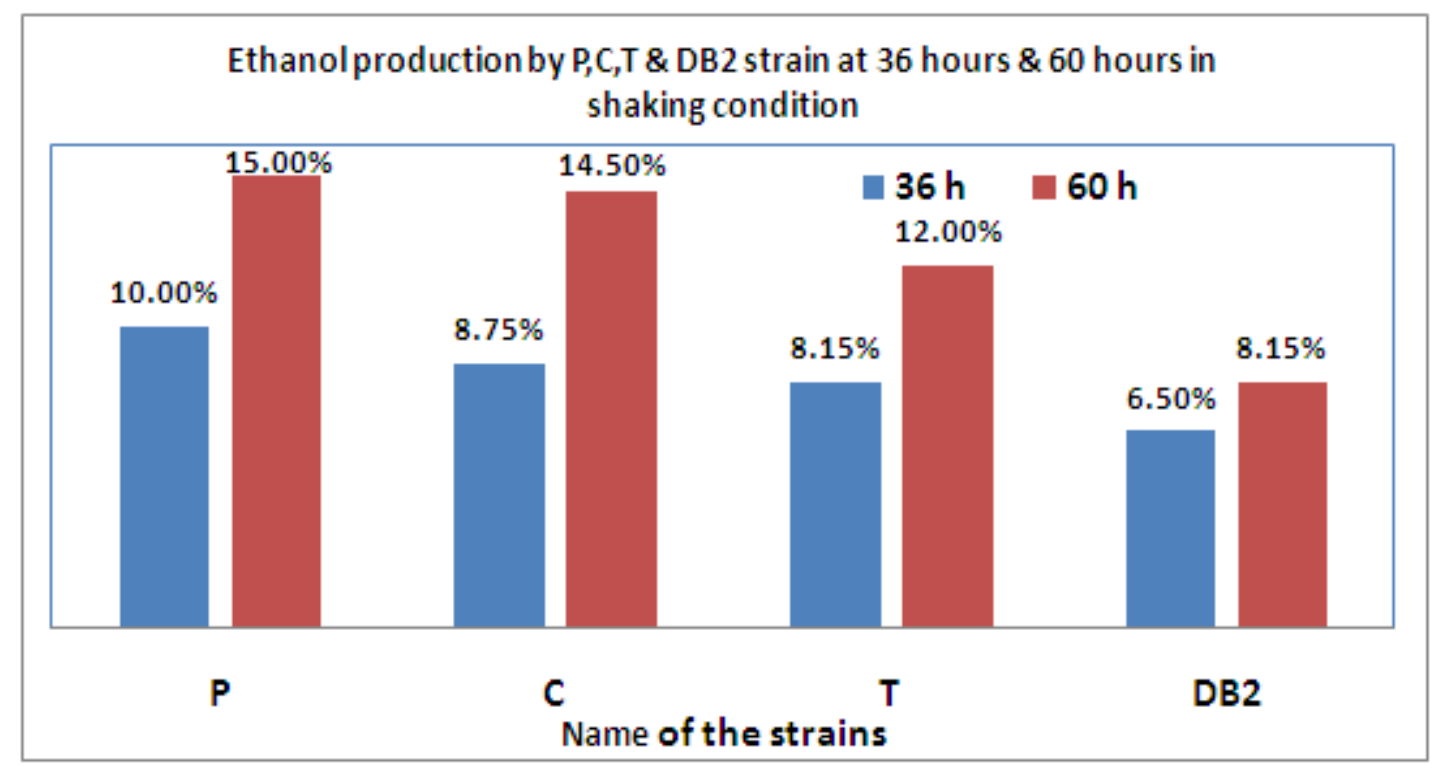

Fig 14. Production of ethanol using initial reducing sugar concentration $5.50 \%$ at $30^{\circ} \mathrm{C}$ in shaking condition

\subsection{Pilot Scale Ethanol Production from Fermentation of Molasses}

Pilot scale production by all the 4 strains was almost similar to that produced at small scale (Shake flask). Ethanol production by $\mathrm{P}$ strain was $13.10 \%$, C strain 
$11.15 \%$, T strain $9.80 \%$ \& DB2 strains $7.85 \%$ at 60 hours.

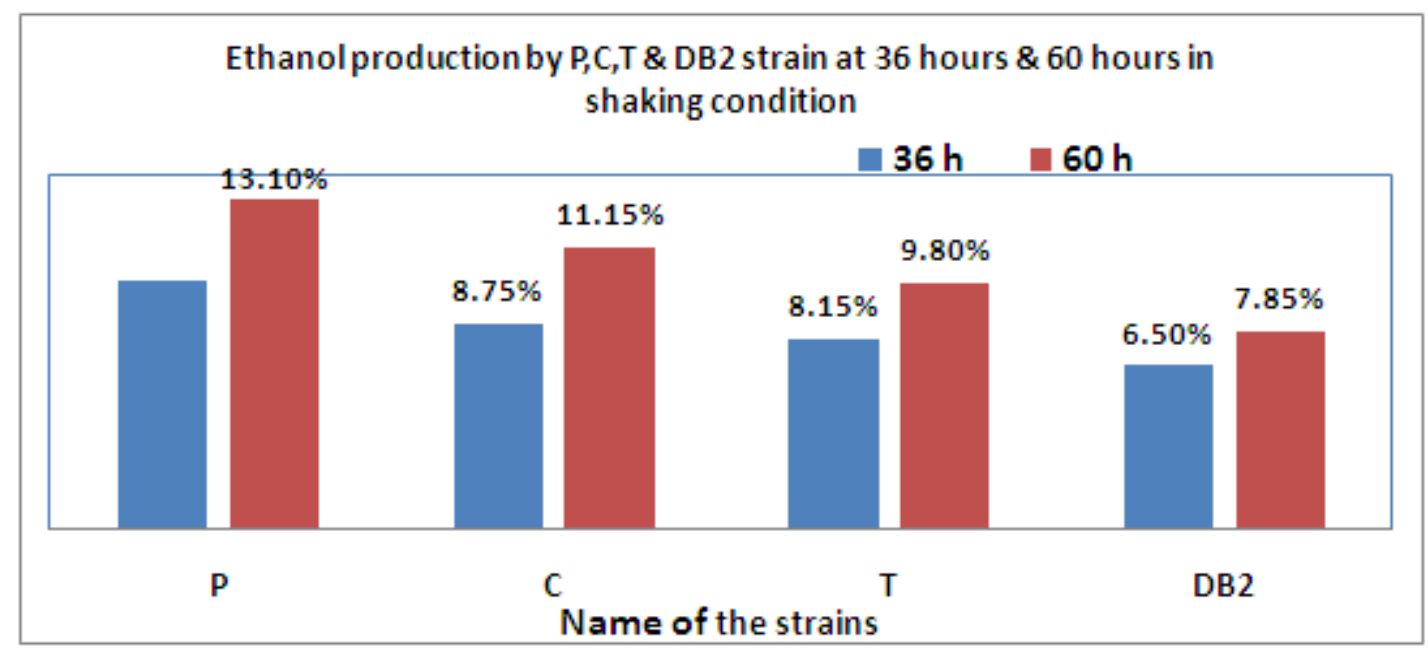

Fig 15. Pilot scale ethanol Production of ethanol using initial reducing sugar concentration $5.50 \%$ at $30^{\circ} \mathrm{C}$ in shaking condition.

\section{Discussion}

Samples were collected from different sources (Baggas, Silages) of agro industries. Based on some morphological \& physiological characterization, presumptive yeast isolates has been selected. Based on the colony characteristics (white and creamy texture), ovoid microscope shape, the presence of ascospore and budding pattern (multipolar), the selected isolate was found to belong to Saccharomyces type unicellular ascomycete according to Lodder $^{(29)}$ and Boekhout and Kurtzman ${ }^{(30)}$ (Fig-3). All the strains were able to produce pseudomycelium.

Molecular identification by DNA sequencing of $5.8 \mathrm{~s}$ rDNA confirmed that strain P is Saccharomyces Unisporus, strain C\& $\mathrm{T}$ areSaccharomyces cerevisiae \& strain DB2 is Candida piceae. Phylogenetic analysis by MEGA 5 revealed that isolate P (identified to be Saccharomyces unisporus), isolate C \& T (identified to be Saccharomyces cerevisiae) are evolutionarily distinct from other Saccharomyces (Fig 13).Isolate DB2 (identified to be Candida piceae) was also in evolutionary distinct position than Candida albicans.

All the strains were tested for fermentation of carbohydrates and they were capable of fermenting five sugars among 11 sugars used as substrates. Glucose, sucrose, maltose, dextrose and fructose were successfully fermented by all the strains but they couldn't ferment lactose, xylose, rhamnose, raffinose, ribose $\&$ arabinose.

There are several potential benefits of thermotolerant yeast to be used in the production of industrial alcohol ${ }^{(38)}$. Thermotolerant yeast exhibits rapid metabolic activity and a high fermentation rate with high product output \& minimized contamination. All the selected strains in this study were thermotolerant \& able to grow up to $46^{\circ} \mathrm{C}$ temperature.
The rate of ethanol production by yeast cells is highly affected by the $\mathrm{pH}$ of the fermentation medium. Most of the yeasts generally showed maximum growth under acidic conditions. Both acidic and basic conditions retard the yeast metabolic pathways and hence the growth of cells ${ }^{(15)}$. All the selected strains were tolerant to wide range of $\mathrm{pH}$. They were able to grow spontaneously from $\mathrm{pH} 2$ to $\mathrm{pH} 10$. Maximum growth was observed at $\mathrm{pH} 6$.

A limitation of ethanol fermentation is the capacity of yeast to tolerate ethanol concentration, because ethanol inhibits alcoholic fermentation. Ekunsanmi and Odunfa ${ }^{(17)}$ assert that the ethanol tolerance is an advantage when a yeast is being considered for industrial use especially where ethanol is being produced. Jimenez and Benitez ${ }^{(19)}$ and Du Preez et al. ${ }^{(39)}$ pointed out that ethanol tolerance is particularly important since ethanol tolerance can hardly be avoided during fermentation although substrate inhibition can be avoided through stepwise addition of substrate. The P, C, T \& DB2 strain was screened for ethanol tolerance and $\mathrm{P} \& \mathrm{C}$ showed up to $18 \%$ ethanol tolerance in YPD liquid growth media but T \& DB2 showed up to $15 \%$. A slow growth rate was observed at $15-20 \%$ ethanol containing media.

All the strains were also osmotolerant as they could tolerate and grow up to $12 \% \mathrm{NaCl}$ containing media. None of the 4 strains studied could tolerate $15 \%$ salt concentration for growth.

The profitability of ethanol production is dependent on availability of sugar cane molasses, price and the quality of molasses (sugar \%) ${ }^{(40)}$. Use of concentrated sugar substrate is one of the ways to obtain high ethanol yield during fermentation. However high substrate concentrations are inhibitory to fermentation due to osmotic stress ${ }^{(41)}$. Isolated yeast stains were able to grow up to $50 \%$ sugar (sucrose) containing liquid YEPD media. Maximum growth was seen in $15 \%$ sugar containing media for all the strains.

$1 \%$ Acetic acid inhibited the growth of all the 4 yeast 
strains. The selected strains were resistant to cycloheximide $(0.0015 \mathrm{~g} / 100 \mathrm{ml})$ \& chloramphenicol $(30 \mu \mathrm{g} / \mathrm{disc})$. The strains were also resistant to hydrogen peroxide $(0.05 \%)$.

Invertase enzyme splits sucrose into glucose and fructose that are easily fermentable by yeast. A wide range of microorganisms produce invertase and can, thus, utilize sucrose as a nutrient. In this study good invertase activity was observed in most of the strains. Isolate $\mathrm{P}, \mathrm{C} \& \mathrm{~T}$ showed maximum invertase activity. So they were able to breakdown rapidly sucrose into glucose \& fructose that is readily usable.

Yeast killer toxins are protein compounds, which are active against members of the same species or closely related species, and the activities of these toxins are analogous to the activities of bacteriocins in bacterial species $^{(42)}$. The capability to produce killer toxin can confer an advantage over more sensitive competitive strains growing in a fermentative process ${ }^{(43)}$. In this study killer toxin producing capability of all the selected 4 strains were observed. Among all the strains only $\mathrm{T}$ strain produced killer toxin and clear zone of inhibition was observed.

In this study, isolate $\mathrm{P}$ produced $15.0 \%$, $\mathrm{C}$ produced $14.50 \%$, T produced $12.00 \%$ \& DB2 produced $8.15 \%$ ethanol at $\mathrm{pH} 6.0,30^{\circ} \mathrm{C}$ temperature and $115 \mathrm{rpm}$ agitation in molasses media with $5.50 \%$ initial reducing sugar concentration within 60 hours.

Semi-Pilot plant studies of ethanol production by these strains with optimized condition have conducted to assess their industrial suitability. Pilot scale production by all the 4 strains was almost similar to that produced at small scale (Shake flask). Isolate $\mathrm{P}$ produced $13.10 \%$, C produced $11.15 \%$, $\mathrm{T}$ produced $9.80 \%$ \& $\mathrm{DB} 2$ produced $7.85 \%$ ethanol at 60 hours.

Productivity can also be improved by mutation through radiation or genetic manipulation. Metabolic pathway engineering to direct ethanol production may be a promising way to improve productivity.

\section{Conclusion}

Among all the 4 isolates the $\mathrm{P}, \mathrm{C}$ and $\mathrm{T}$ would be useful to produce ethanol industrially in Bangladesh from molasses which is a very cheap and available raw material. Such industry will save foreign currency to import ethanol and will reduce dependency on fossil fuels. Productivity can also be improved by mutation through radiation or genetic manipulation. Metabolic pathway engineering to direct ethanol production may a promising way to improve productivity.

\section{References}

[1] Nadir, N., Mel, M.., Karim, M.I.A., Yunus, R.M. Comparison of sweet sorghum and cassava for ethanol production by using Saccharomyces cerevisiae.J. App. Sci.,2009; 9(17): 3068-3073
[2] Ibeto CN, Ofoefule AU, Agbo KE. A global overview of biomass potentials for bioethanol production: A renewable alternative fuel. Trends App. Sci. Res.,2011; 6(5): 410-425

[3] Jegannathan KR, Chan E, Ravindra P. Biotechnology in Biofuels- A cleaner technology. J. App. Sci.,2011; 11(13): 2421-2425

[4] Chaudhury N, Qazi JI. Microbiological Saccharification and ethanol production from sugarcane bagasse.Biotechnol.,2006; 5(4): 517-521.

[5] Noor AA, Hameed A, Bhatti KP, Tunio SA. Bio-ethanol fermentation by the bioconversion of sugar from Dates by Saccharomyces cerevisiae strains ASN-3 and HA-4. Biotechnol.,2003; 2(1): 8-17.

[6] Somda MK, Savadogo A, Ouattara CAT, Ouattara AS, Traore AS. Improvement of Bioethanol production using amylasic properties from Bacillus licheniformis and yeasts strains fermentaiton for Biomass valorization. Asian J.Biotechnol.,2011a; 3(3): 254-261.

[7] Somda MK, Savadogo A, Barro N, Thonart P, Traore AS. Effects of mineral salts in fermentation process using mango residues as carbon source for bioethanol production. Asian J.Biotechnol.,2011b; 3(1): 29-38.

[8] Somda MK, Savadogo A, Ouattara CAT, Ouattara AS, Traore AS. Thermotolerant and Alcohol-tolerant yeasts targeted to optimize hydrolyzation from mango peel for high bioethanol production. Asian J.Biotechnol.,2011c; 3(1): 7783.

[9] Khongsay N, Laopaiboon L, Laopaiboon P. Growth and Batch fermentation of Saccharomyces cerevisiae on sweet sorghum stem juice under normal and very high gravity conditions. Biotechnol.,2010; 9(1): 9-16

[10] Boboye B, Dayo-Owoyemi I. Evaluation of Dough Sensory Properties Impacted by Yeasts Isolated from Cassava. J. Appl. Sci.,2009; 9(4): 771-776.

[11] Kurtzman CP, Robnett CJ, Ward JM, Bravton C, Gorelic P, Walsh TM(2005)Multigene phylogenetic analysis of pathogenic Candida species in the Kazachstania(Arxiozyma) telluriscomplex and description of their ascosporic states as Kazachstania bovina sp. nov., K. heterogenicasp. nov., $K$. pintolopesii sp. nov., and $K$. slooffiaesp. nov.J.Clin.Microbiol.,2005; 43(1): 101-111.

[12] Kreger-Van Rij NJW. The Yeast a Taxonomic Study. New York: Elsevier Science Publishing Company,1984; pp. 1082.

[13] Warren P, Shadomy L. Yeast fermentation broth base with carbohydrate and Durham tube. In: Manual of Clinical Microbiology.5th ed. Washington D.C., 1991.

[14] Osman ME, Khattab OH, Hammad IA, El-Hussieny NI. Optimization of Bio-Fuel Production by Saccharomyces cerevisiae Isolated from Sugar Cane Bagasse. J. Am. Sci.,2011; 7(5):485-492

[15] Willaert R, Viktor AN. Primary beer fermentation by immobilized yeast - a review on flavor formation and control strategies. J. Chem. Technol.Biotechnol.,2006; 81: 1353-1367.

[16] Wayman M, Parekh SR. Microbiology of fermentation catalysts.In Biotechnology of Biomass Conversion. Milton Keynes: Open University press. 1990; pp. 75-100. 
[17] Ekunsanmi TJ, Odunfa SA. Ethanol tolerance, sugar tolerance and invertase activities of some yeasts strains isolated from steep water of fermenting cassava tubers. J. App.Bacteriol.,1990; 69: 672-675.

[18] Kirby WWM, Bauer AW, Sherris JC. Antibiotic susceptibility testing by standardized single disk method. Am. J.Clin.Pathol.,1996; 45: 493-496.

[19] Jimenez J, Benitez T. Characterization of wine yeasts for ethanol production. App.Microbiol.Biotechnol.,1986; 25: 150-154.

[20] Bernfield P. Enzymes of starch degradation and synthesis. Adv.Enzymol.,1951; 12: 379-481.

[21] Ribereau-Gayon P, Dubordieu D, Doneche B, Lonvaud A.Handbook of Enology: The Microbiology of Wine and Vinifications. JohnWiley and Sons, Chichester2000; 1:454.

[22] Moslem MA,Bahkali AH, Abd-Elsalam KA, Wit PJ. An efficient method for DNA extraction from Cladosporioid fungi.Genet. Mol.Res., 2010;9: 2283-2291.

[23] Fakruddin M, IslamS, AhmedMM, ChowdhuryA, HoqueMM. Development of Multiplex PCR (Polymerase Chain Reaction) Method for Detection of Salmonella spp. and Vibrio parahaemolyticus from Shrimp Samples of Bangladesh. Asian J. Biol. Sci.,2012a; 5(2): 76-85.

[24] Borneman J, Hartin RJ. PCR primers that amplify fungal rRNA genes from environmental samples.Appl. Environ.Microbiol.,2000; 66:4356-4360.

[25] Tamura K, Peterson D, Peterson N, Stecher G, Nei M, Kumar S. MEGA5: Molecular Evolutionary Genetics Analysis using Maximum Likelihood, Evolutionary Distance, and Maximum Parsimony Methods. Mol. Biol.Evol.,2011; 28: 2731-2739.

[26] Fakruddin M, Quayum MA, Ahmed MM, Choudhury N. Analysis of key factors affecting ethanol production by Saccharomyces cerevisiae IFST-072011. Biotechnol.,2012b; 11(4): 248-252.

[27] Miller GL. Use of dinitrosalicylic acid reagent for determination of reducing sugar. Anal. Chem.,1959; 31:426428.

[28] Conway EJ.Micro-diffusion analysis and volumetric error. Crosby Lockwood and Son, London, 1939.

[29] Lodder J. The yeasts: A Taxonomic study. NorthHoll and Publishing, Amsterdam, 1971.

[30] Boekhout T, Kurtzman CP. Principles and methods used in yeast classification, and an overview of currently accepted yeast genera. In Wolf, $\mathrm{K}$. Nonconventional Yeasts in
Biotechnology: A Handbook. Springer-Verlag: Heidelberg. 1996; pp. 1-99.

[31] Kurtzman CP, Fell JW.The Yeasts, a Taxonomic Study. Fourth Edition. Amsterdam: Elsevier Science Publishing Company.1997;pp-1055.

[32] Gimeno CJ, Ljungdahl PO, Styles CA, Fink GR. Unipolar cell divisions in the yeast $S$. cerevisiae lead to filamentous growth: regulation by starvation and RAS. Cell,1992; 68: 1077-1090.

[33] Ueno R, Urano N, Kimura S. Characterization of thermotolerant, fermentative yeasts from hot spring drainage. Fish Sci.,2001; 67: 138-145.

[34] Hampsey M. A Review of Phenotypes in Saccharomyces cerevisiae. Yeast,1997; 13: 1099-1133.

[35] Krems B, Charizanis C, Entian KD. Mutants of Saccharomyces cerevisiae sensitive to oxidative and osmotic stress. Curr.Genet.,1995; 27: 427-434

[36] Saitou N, Nei M.The neighbor-joining method: A new method for reconstructing phylogenetic trees. Mol, Biol.Evol., 1987; 4:406-425.

[37] Nei M, Kumar S. Molecular Evolution and Phylogenetics. Oxford University Press, New York, 2000.

[38] Roehr M. The Biotechnology of Ethanol: Classical and Future Applications. Chichester: Wiley-VCH. 2001; pp.232.

[39] Du Preez JC, Bosch MN, Prior BA.Temperature profiles of growth and ethanol tolerance of the xylose fermenting yeasts Candida shemataeand Pichiastipitis.App.Microbiol.Biotechnol.,1987; 25: 521-525.

[40] Arshad M, Zia MA, Asghar M, Bhatti H. Improving bioethanol yield: Using virginiamycin and sodium flouride at a Pakistani distillery. Afr. J.Biotechnol.,2011; 10(53):1107111074

[41] Jones RK, Duncan HE, Payne GA, Leonard KJ.Factors influencing infection by Aspergillus flavus in silk-inoculated corn. Plant Disease, 1980; 64: 859 - 863.

[42] Lowes KF, Shearman CA, Payne J, McKenzie D, Archer DB, Merry RJ, Gasson MJ.Prevention of yeast spoilage in feed and food by the yeast mycocin HMK. Appl.Env.Microbiol. 2000; 66(3): 1066-1076.

[43] Soares GAM, Sato HH. Characterization of the Saccharomyces cerevisiae Y500-4L killer toxin. Braz. J.Microbiol.,2000; 31: 291-297. 